\title{
PRÁTICA PEDAGÓGICA DO PROFESSOR DE EDUCAÇÃO FÍSICA NA ESCOLA: DIFICULDADES PERCEBIDAS POR UMA EQUIPE ES- COLAR NA CIDADE DE SÃO PAULO ${ }^{1}$
}

\author{
Daniel Teixeira Maldonado \\ Universidade São Judas Tadeu, São Paulo, São Paulo, Brasil \\ Sheila Aparecida Pereira dos Santos Silva \\ Universidade São Judas Tadeu, São Paulo, São Paulo, Brasil
}

\begin{abstract}
Resumo
O objetivo deste estudo foi compreender os fatores que dificultam o trabalho pedagógico em Educação Física escolar por meio de uma pesquisa qualitativa, descritiva, realizada em uma escola municipal da cidade de São Paulo. Os principais fatores encontrados foram: descontentamento profissional, jornada de trabalho extensa, baixa remuneração, formação profissional insuficiente e desorganização do trabalho. Feita análise e classificação dos fatores encontrados, concluímos que eles estão presentes nas dimensões Sociopolítica/Cultural, Institucional/Organizacional, Instrucional/Pedagógica, sendo mais frequentes nas duas primeiras e, portanto, o professor não é o único responsável pelo descompasso entre o ideário das propostas curriculares oficiais e sua implementação nas escolas.
\end{abstract}

Palavras-chave: Educação física. Prática pedagógica. Cotidiano escolar. Dificuldade.

\section{Introdução}

Desde os anos de 1980 observamos discussões acadêmicas na área da Educação Física (EF) visando à definição de sua identidade epistemológica, com consequências para suas práticas pedagógicas na escola. Podemos dizer que, na primeira década do séc. XXI, as propostas curriculares oficiais brasileiras de Educação Física Escolar (EFE) já se orientavam, predominantemente, por um novo paradigma teórico-metodológico.

Essa mudança paradigmática é fruto do embate, muitas vezes conflituoso segundo Silva (2013), entre defensores de diferentes discursos sobre as finalidades e objetivos da EFE que, ora focalizavam o desenvolvimento motor dos discentes (TANI et al., 1988), ora outros aspectos como a promoção da educação psicomotora (FREIRE, 1989; LE BOULCH, 1983), o estímulo a saúde dos alunos (GUEDES, 1999), o desenvolvimento da criticidade em relação às manifestações da cultura corporal de movimento (COLETIVO DE AUTORES, 2009; KUNZ, 2001), ou a luta contra as desigualdades sociais vinculadas às práticas corporais (NEIRA; NUNES, 2009).

Ferreira (2014), por sua vez, menciona que emergiu uma compreensão de que a EFE não se esgota na dimensão do saber fazer, e envolve, também, um saber sobre e um saber ser.

A partir deste cenário de mudança paradigmática, pode-se afirmar que, hoje, predomina nas propostas curriculares nacionais o embasamento teórico que manifesta o entendimento que a EFE possui como objeto pedagógico a cultura corporal de movimento, o que supera reducionismos presentes em outras concepções, ainda que muitas vezes essa superação ocorra

\footnotetext{
${ }^{1} \mathrm{O}$ presente trabalho contou com apoio financeiro da Universidade São Judas Tadeu para a sua realização.
} 
apenas nos textos de fundamentação das propostas e não se traduza em práticas pedagógicas coerentes com o novo ideário.

As formas de pensar, em geral, precedem as formas de colocar as intencionalidades em prática. Compreender o que acontece cotidianamente nas escolas ainda é um grande desafio para os pesquisadores no sentido de entender as condições responsáveis pelo distanciamento entre os discursos e as práticas.

Essa compreensão implica, entre outros aspectos, em pesquisar o professor como sujeito e a escola como uma instituição viva onde se manifestam diferentes roupagens de EFE. Conforme recomendam Rodrigues e Bracht (2010), cabe aos pesquisadores compreender e analisar as repercussões que uma dada inserção da EF causa em uma realidade escolar específica.

Maldonado, Silva e Miranda (2014), ao traçarem o estado da arte das pesquisas sobre o cotidiano da EFE no Brasil, mostraram que 9,3\% delas tinham como tema a complexidade do cotidiano escolar, $3,6 \%$ as condições de trabalho e 1,6\% a construção curricular, ou seja, temas como diagnóstico de como os professores ensinam $(37,1 \%)$, formação profissional $(18,6 \%)$, inovações na prática pedagógica $(17,5 \%)$ atraíram mais a atenção dos pesquisadores nos artigos publicados entre 1975 e outubro de 2013 em 63 periódicos científicos.

Autores da área da Educação (PÉREZ GÓMEZ, 2001; SACRISTÁN, 1998) alertam que a escola e os professores não são entes isolados do contexto social em que vivem, o que nos leva a crer que seria equivocado tentar compreender seu cotidiano profissional sem mencionar a existência de aspectos sociopolíticos e culturais influenciando os sistemas educativos e as práticas pedagógicas. Além disso, existe nas escolas uma cultura criada pelos docentes que implica em diferentes formas de aplicar estratégias de ensino, cultura essa que também exige esforços de pesquisa para que seja possível compreendê-la.

Desvendar as tramas presentes no cotidiano escolar é uma tarefa complexa, exige a identificação dos aspectos que a compõem e o relacionamento entre eles. Quando pensamos especificamente nas aulas de EFE não é diferente, já que a ação do docente é influenciada por fatores pedagógicos, organizacionais, sociopolíticos e culturais (CAPARROZ, 2007; REZER; FENSTERSEIFER, 2008) e sua percepção sobre a realidade pode encorajá-lo ou desencorajálo a colocar em prática novas estratégias didáticas e demais ações que coadunem com um novo ideário educativo.

Todo esse cenário nos levou a indagar a respeito dos aspectos que influenciam a prática pedagógica dos professores de EF nas escolas da cidade de São Paulo. Será que percebem que há barreiras, limites ou fatores que dificultam colocar em prática suas intenções pedagógicas? Será que a direção e a coordenação pedagógica da escola percebem a realidade da EFE da mesma forma que os docentes de EFE?

Diante destas questões, e como um primeiro passo de aproximação do fenômeno complexo que é o cotidiano escolar, propusemos como objetivo desta pesquisa descrever a percepção de um grupo de profissionais da Educação, dentre eles três docentes de EFE, sobre a realidade vivida no cotidiano escolar com foco nas dificuldades que eles relacionam à efetivação da prática pedagógica neste componente curricular.

\section{Método da Pesquisa}

Realizamos uma pesquisa qualitativa de cunho descritivo em uma escola da rede municipal de São Paulo, Diretoria Regional de Educação (DRE) Penha, mediante aprovação do Comitê de Ética em Pesquisa da Universidade São Judas Tadeu, com número de protocolo 099/2011.

Foram sujeitos da pesquisa um Diretor, dois Coordenadores Pedagógicos e três professores de EF, constituindo uma amostra não probabilística atípica, escolhida a partir do pro- 
blema de pesquisa (LAVILLE; DIONNE, 1999), bem como a facilidade de acesso e conhecimento prévio das peculiaridades da região pesquisada, já que um dos pesquisadores atuou em uma escola que faz parte da mesma DRE.

A pesquisa foi realizada em três etapas, de acordo com o sugerido por Jaramillo Echeverri (2005): a) Pré-configuração do universo da pesquisa; b) Configuração do Universo da Pesquisa; c) Reconfiguração do Universo da pesquisa. A coleta dos dados ocorreu em 2012 e durou aproximadamente seis meses.

a) Pré-configuração do Universo da Pesquisa: nessa etapa ocorreram os primeiros contatos com a escola e com os sujeitos da pesquisa; a coleta das assinaturas dos Termos de Autorização para realização da pesquisa e dos Termos de Consentimento Livre e Esclarecido; avaliação do Projeto Pedagógico da Escola; observação da dinâmica da escola e de pelo menos duas aulas de EF dos professores pesquisados.

b) Configuração do Universo da Pesquisa: nessa etapa ocorreram as entrevistas semiestruturadas, com questões abertas e fechadas; foi realizada outra rodada de observações e o registro em diários de campo de sessenta aulas, e consultas aos planos anuais de ensino dos/das professores/as de EF. As entrevistas foram realizadas individualmente, em local e horário antecipadamente agendado, gravadas em áudio, e posteriormente transcritas para possibilitar as análises. Neste material foram identificadas as unidades de significado, posteriormente elaboradas as matrizes ideográficas e as nomotéticas, de acordo com o recomendado por Martins \& Bicudo (2005). As matrizes nomotéticas foram organizadas em categorias temáticas para possibilitar a análise e discussão dos resultados. Os registros das aulas e a análise dos Planos da Escola e dos professores foram utilizados como recursos auxiliares para a compreensão do conteúdo das entrevistas e discussão dos resultados.

c) Reconfiguração do Universo da Pesquisa: nessa etapa, os resultados coletados foram apresentados aos sujeitos, separadamente, tendo um momento de devolutiva junto aos professores de EF e outro momento junto aos coordenadores pedagógicos e direção. O diálogo e reflexão com eles a respeito da realidade pesquisada serviram tanto como validação dos resultados, como para sua complementação, além de, possivelmente, ter contribuído como estímulo à reflexão sobre suas práticas educativas.

\section{Resultados e discussão}

Essa escola iniciou suas atividades em 1958 e atendia alunos do $1^{\circ}$ ao $9^{\circ}$ ano do Ensino Fundamental, além de estudantes da Educação de Jovens e Adultos (EJA) no período noturno. Contava com 40 professores no Ensino Fundamental e seis professores na EJA. Desses profissionais, $27 \%$ trabalhavam em jornada especial de formação, que é um tipo de jornada em que o professor possui um horário remunerado para estudar com vistas a aprimorar sua atuação. Dos professores de EF que participaram da pesquisa, apenas um atendia ao requisito de possuir um número mínimo de aulas atribuídas para poder realizar a formação dentro do horário de trabalho.

Os três docentes eram licenciados em EF e sua formação continuada ocorria por meio dos escassos cursos oferecidos nas redes de ensino em que trabalhavam (municipal, estadual e/ou particular). A diretora e um dos coordenadores pedagógicos acumulavam cargos públicos.

Dois professores possuíam mais de 10 anos de experiência profissional na área escolar e um deles estava no seu primeiro ano de atuação. A diretora e os coordenadores eram licenciados em sua área de atuação docente e possuíam mais de 15 anos de experiência nessa rede de ensino. 
Ao estar na escola durante essa etapa da pesquisa, o pesquisador observou algumas condições nas quais os docentes de EF ministravam suas aulas: espaço limitado, dificuldade em lidar com os alunos, número de 30 a 35 estudantes em cada turma.

Ao final da etapa da Configuração do Universo da Pesquisa, os resultados das entrevistas realizadas com a diretora, os coordenadores pedagógicos e com os professores de EF geraram perfis individuais (análise ideográfica), que foram posteriormente reunidos no formato de quatro matrizes nomotéticas (visão de aspectos gerais) que serão apresentadas a seguir. A primeira (Quadro 1) se refere aos resultados das entrevistas, detalhados por profissional entrevistado, e as três restantes (Quadros 2, 3 e 4) associam os resultados das entrevistas e das observações, classificados nas dimensões Sociopolítica/Cultural; Institucional/Organizacional; e Instrucional/Pedagógica; tendo como referência os estudos de André (2008). Para essa autora, a compreensão das vivências do cotidiano da escola baseia-se nessas três dimensões que devem ser analisadas como uma unidade de múltiplas relações.

A leitura das linhas horizontais da matriz nomotética permite visualizar quantas pessoas mencionaram aquela unidade significativa e, na vertical, permite visualizar todas as unidades significativas identificadas no discurso de cada entrevistado, cuja legenda para designar sua função é: D - Diretor; C - Coordenador Pedagógico; P - Professor de EF.

\section{Quadro 1 - Fatores que dificultam a prática pedagógica do professor de EF}

\begin{tabular}{|c|c|c|c|c|c|c|c|}
\hline \multirow{2}{*}{\begin{tabular}{|l} 
Unidades de Significado \\
\end{tabular} Sujeitos Pesquisados } & \multicolumn{6}{|c|}{ Comunidade escolar } & \multirow[t]{2}{*}{ Total } \\
\hline & $\mathbf{D}$ & C1 & $\mathrm{C2}$ & P1 & $\mathbf{P 2}$ & P3 & \\
\hline Espaço físico inadequado & $\mathrm{x}$ & $\mathrm{X}$ & $\mathrm{X}$ & $\mathrm{x}$ & $\mathrm{x}$ & $\mathrm{X}$ & 6 \\
\hline Indisciplina dos alunos & $\mathrm{x}$ & $\mathrm{x}$ & $\mathrm{X}$ & & $\mathrm{x}$ & $\mathrm{x}$ & 5 \\
\hline Jornada de trabalho extensa & $\mathrm{x}$ & $\mathrm{x}$ & $\mathrm{X}$ & $\mathrm{x}$ & $\mathrm{x}$ & & 5 \\
\hline Falta de materiais & & $\mathrm{x}$ & $\mathrm{X}$ & $\mathrm{x}$ & $\mathrm{x}$ & $\mathrm{x}$ & 5 \\
\hline Cultura do aluno com os estudos & & $\mathrm{x}$ & $\mathrm{X}$ & $\mathrm{x}$ & $\mathrm{x}$ & $\mathrm{x}$ & 5 \\
\hline Formação continuada insuficiente na escola & $\mathrm{x}$ & $\mathrm{x}$ & $\mathrm{X}$ & $\mathrm{x}$ & & & 4 \\
\hline Formação continuada insuficiente na rede & $\mathrm{x}$ & $\mathrm{x}$ & $\mathrm{X}$ & $\mathrm{x}$ & & & 4 \\
\hline Falta de organização da rede municipal & $\mathrm{x}$ & & $\mathrm{X}$ & & $\mathrm{x}$ & $\mathrm{x}$ & 4 \\
\hline Falta de organização da escola & $\mathrm{X}$ & & & $\mathrm{x}$ & $\mathrm{X}$ & $\mathrm{x}$ & 4 \\
\hline Dificuldade dos alunos com os conteúdos & $\mathrm{x}$ & $\mathrm{x}$ & & $\mathrm{x}$ & & $\mathrm{x}$ & 4 \\
\hline Influências climáticas para as aulas & $\mathrm{x}$ & & & $\mathrm{x}$ & $\mathrm{X}$ & & 3 \\
\hline Relação escola-comunidade inadequada & $\mathrm{x}$ & & $\mathrm{X}$ & & & & 2 \\
\hline Relação interpessoal profissional inadequada & & & & & $\mathrm{x}$ & $\mathrm{x}$ & 2 \\
\hline Falta de condições para a educação inclusiva & & $\mathrm{x}$ & & & & $\mathrm{x}$ & 2 \\
\hline Barulho causado pelas aulas de EF & & & & $\mathrm{x}$ & & & 1 \\
\hline Alteração da função social da escola & $\mathrm{x}$ & & & & & & 1 \\
\hline Falta de trabalho coletivo & $\mathrm{x}$ & & & & & & 1 \\
\hline Visão da disciplina de EF & $\mathrm{x}$ & & & & & & 1 \\
\hline Baixa remuneração & & $\mathrm{x}$ & & & & & 1 \\
\hline Descontentamento profissional & & $\mathrm{x}$ & & & & & 1 \\
\hline Trânsito para chegar até a unidade escolar & & $\mathrm{x}$ & & & & & 1 \\
\hline Resistência dos professores com novos currículos & & & $\mathrm{X}$ & & & & 1 \\
\hline Relação interpessoal entre os alunos inadequada & & $\mathrm{x}$ & & & & & 1 \\
\hline
\end{tabular}

Fonte: Elaborado pelos autores, 2012.

Durante as observações, de acordo com o julgamento do pesquisador, foram identificados alguns fatores que podem dificultar a prática pedagógica dos docentes de EF. Alguns deles foram mencionados nas entrevistas, mas alguns não. Os fatores não mencionados foram: mau odor no local onde acontecem as aulas de EF, alunos transferidos para a escola com o ano letivo já iniciado, número elevado de alunos por turma, falta de liberação dos responsáveis para os alunos participarem de atividades em um parque próximo da escola, restrição médica para participar das aulas. 
Em busca de compreender a natureza desses fatores que dificultam a prática pedagógica dos docentes de EF nessa escola, os classificamos nas dimensões: a) Sociopolítica/Cultural; b) Institucional/Organizacional; e c) Instrucional/Pedagógica. A dimensão Sociopolítica/Cultural se refere ao contexto mais amplo, aos determinantes macroestruturais da prática educativa. O pesquisador, em seu trabalho analítico nessa dimensão, realiza reflexões sobre o contexto histórico, sobre as forças políticas e sociais, sobre as concepções e os valores presentes na sociedade, considera sua totalidade e suas múltiplas determinações buscando um nível mais profundo de investigação da prática escolar. (ANDRÉ, 2008).

A análise na dimensão Institucional/Organizacional torna possível compreender a rede de relações que ocorrem no cotidiano escolar manifestas na organização do trabalho pedagógico, nas estruturas de poder e de decisão, nos níveis de participação dos seus agentes, na disponibilidade de recursos humanos e de materiais (ANDRÉ, 2008).

A dimensão Instrucional/Pedagógica se situa nas vivências escolares de ensino no qual se dá o encontro entre professor-aluno-conhecimento. A análise, nessa dimensão, focaliza os objetivos e conteúdos de ensino, as atividades, o material didático, a linguagem e outros meios de comunicação entre educador e educando, e as maneiras de avaliação do ensino e da aprendizagem. (ANDRÉ, 2008).

Nos Quadros 2, 3 e 4 elencamos os fatores que dificultam a prática pedagógica do professor de EF nas escolas municipais de São Paulo na percepção dos entrevistados, classificados nas três dimensões mencionadas. Essas percepções foram colocadas ao lado do que se encontra na literatura especializada da área a respeito de dificuldades enfrentadas por docentes que atuam em diferentes regiões do país (BERNARDI; MOLINA NETO, 2016; BOSSLE; MOLINA NETO, 2009; BOSSLE; MOLINA NETO; WITTIZORECKI, 2013; CLARO JUNIOR; FILGUEIRAS, 2009; DAMAZIO; SILVA, 2008; FOLLE; NASCIMENTO, 2011; GASPARI et al., 2006; LEVANDOSKI; OGG; CARDOSO, 2011; MACHADO et al., 2010; MAGALHÃES; MARTINELI, 2011; MIRON; COSTA, 2014; OLIVEIRA; SILVA; MOLINA NETO, 2011; PORATH et al., 2011; REIS, 2009; ROSSI; HUNGER, 2013; SANT'ANA; NASCIMENTO; AZEVEDO, 2012; SANTINI; MOLINA NETO, 2005; TENÓRIO; TASSITANO; LIMA 2012; TOKUYOCHI et al., 2008) para que fosse possível comparar-se o contexto pesquisado apresentava similaridades com a realidade descrita nessa literatura.

No Quadro 2, a primeira coluna contém os fatores complicadores identificados na pesquisa referentes à dimensão Sociopolítica/Cultural. Nas colunas 2, 3 e 4 está assinalado a técnica de pesquisa associada ao segmento do Ensino Fundamental onde foram feitos os registros: Fund. $1=1^{\circ}$ ao $5^{\circ}$ ano, Fund. $2=6^{\circ}$ ao $9^{\circ}$ ano. Na última coluna foi assinalada a presença desses fatores na literatura levantada.

Quadro 2 - Fatores que dificultam a prática pedagógica do professor de EF na dimensão Sociopolítica/Cultural.

\begin{tabular}{|c|c|c|c|c|}
\hline $\begin{array}{l}\text { Fatores classificados na dimensão } \\
\text { Sociopolítica/Cultural }\end{array}$ & Entrevista & $\begin{array}{c}\text { Observação } \\
\text { Fund. } 1\end{array}$ & $\begin{array}{c}\text { Observação } \\
\text { Fund. } 2\end{array}$ & Literatura \\
\hline Indisciplina dos alunos & $\mathrm{X}$ & $\mathrm{X}$ & $\mathrm{X}$ & $\mathrm{x}$ \\
\hline $\begin{array}{l}\text { Falta de condições para a educação in- } \\
\text { clusiva }\end{array}$ & $\mathrm{x}$ & $\mathrm{X}$ & $\mathrm{x}$ & $\mathrm{x}$ \\
\hline Espaço físico inadequado & $\mathrm{x}$ & $\mathrm{X}$ & $\mathrm{x}$ & $\mathrm{x}$ \\
\hline Influências climáticas para as aulas & $\mathrm{x}$ & $\mathrm{X}$ & $\mathrm{x}$ & $\mathrm{x}$ \\
\hline Cultura do aluno com os estudos & $\mathrm{x}$ & $\mathrm{X}$ & $\mathrm{x}$ & \\
\hline Número elevado de alunos por turma & & $\mathrm{X}$ & $\mathrm{x}$ & $\mathrm{x}$ \\
\hline $\begin{array}{l}\text { Formação continuada insuficiente na } \\
\text { rede }\end{array}$ & $\mathrm{x}$ & & & $\mathrm{x}$ \\
\hline Baixa remuneração & $\mathrm{x}$ & & & $\mathrm{x}$ \\
\hline Jornada de trabalho extensa & $\mathrm{x}$ & & & $\mathrm{x}$ \\
\hline
\end{tabular}




\begin{tabular}{|l|c|c|c|c|}
\hline Alteração da função social da escola & $\mathrm{x}$ & & & $\mathrm{x}$ \\
\hline $\begin{array}{l}\text { Relação interpessoal entre os alunos } \\
\text { inadequada }\end{array}$ & $\mathrm{x}$ & & & $\mathrm{x}$ \\
\hline $\begin{array}{l}\text { Restrição médica para participar das } \\
\text { aulas }\end{array}$ & & $\mathrm{X}$ & & $\mathrm{x}$ \\
\hline Descontentamento profissional & $\mathrm{x}$ & & & \\
\hline $\begin{array}{l}\text { Resistência dos professores com novos } \\
\text { currículos }\end{array}$ & $\mathrm{x}$ & & & \\
\hline $\begin{array}{l}\text { Trânsito para chegar até a unidade esco- } \\
\text { lar }\end{array}$ & $\mathrm{x}$ & & $\mathrm{x}$ & \\
\hline $\begin{array}{l}\text { Falta de liberação dos responsáveis para } \\
\text { participar de atividades em um parque } \\
\text { próximo da escola }\end{array}$ & & & & \\
\hline Sentir-se intimidado pelos alunos & & & & $\mathrm{x}$ \\
\hline Uso de drogas & & & & $\mathrm{x}$ \\
\hline Alunos faltosos & & & & $\mathrm{x}$ \\
\hline Exposição do professor na quadra & & & & $\mathrm{x}$ \\
\hline Número reduzido de aulas & & & & \\
\hline
\end{tabular}

Fonte: Elaborado pelos autores 2016.

A maioria dos fatores que dificultam a prática pedagógica dos docentes de EFE foi classificada na dimensão Sociopolítica/Cultural. Esse resultado convergiu com os resultados presentes na literatura da área de EFE.

Ao analisar os fatores que interferem na prática pedagógica dos professores, Sacristán (1998) menciona que existe um contexto exterior ao meio pedagógico que influencia de forma significativa a organização das aulas e o que se ensina na escola.

As pressões econômicas e políticas, os valores que representam o grupo que encontrase no poder, regulamentações administrativas da prática escolar e do sistema educativo, a influência da família sobre os conteúdos estudados, o sistema de produção de materiais didáticos que os professores utilizam e as pressões dos meios acadêmicos e culturais para legitimar aquilo que se considera importante ensinar na escola são fatores que controlam a prática pedagógica dos professores.

Sacristán (1998) destaca, também, que as aulas são influenciadas pela estrutura da escola, pelas relações internas no ambiente escolar, as formas de organização dos professores, as atitudes da coordenação pedagógica, as atividades culturais realizadas na escola, a organização do espaço, a disposição do tempo.

Em nossa pesquisa, fatores como a cultura dos alunos em relação aos estudos, a resistência dos professores a novos currículos, o tráfego intenso para chegar até a escola e a falta de liberação dos responsáveis para os alunos participarem de atividades em um parque próximo da escola foram dificuldades mencionadas e ainda não registradas na literatura da EFE.

Para os profissionais pesquisados, os fatores macroestruturais são os principais entraves para materializar a prática pedagógica em EFE. Segundo eles, para essa realidade ser modificada, seriam necessários mais investimentos por parte dos governantes nas esferas municipal, estadual e federal.

Corroborando com os resultados encontrados em nossa pesquisa e os estudos da literatura especializada na área da EFE, Libâneo (2015) afirma que os governos têm sido incapazes de garantir a valorização salarial dos professores e condições de trabalho adequadas aos docentes, levando a uma degradação social e econômica da profissão e a um rebaixamento evidente da qualificação profissional dos professores em todo o país, interferindo de forma negativa na prática pedagógica dos profissionais da escola.

Ao mesmo tempo em que a mídia, profissionais de diferentes profissões, políticos e outros interessados na qualidade da educação falam da valorização da educação escolar de todos os alunos para a cidadania, para o consumo e para a preparação voltada ao mercado de 
trabalho, continuam a serem praticados salários baixos, condições de trabalho inadequadas e um reduzido empenho na melhoria da formação profissional dos docentes (LIBÂNEO, 2015).

Tardif (2013), por sua vez, descreve que desde a década de 1980 passou a existir um movimento de profissionalização no ensino com o objetivo de elevar o status dos professores, valorizar o seu trabalho junto à opinião pública, aumentar a sua autonomia e melhorar suas condições de trabalho, porém, depois de mais de 30 anos de iniciado esse movimento, ainda são observados vários fatores que bloqueiam o seu desenvolvimento.

Os professores possuem salários muito menores do que os profissionais que atuam em profissões mais reconhecidas; muitos ainda não possuem empregos estáveis e permanentes; houve aumento da complexidade e intensificação do trabalho docente. Tardif (2013) relata, ainda, que os professores passaram a ser obrigados a fazer mais com menos recursos, houve uma diminuição do tempo gasto com os alunos devido à diversificação dos seus papéis já que não atuam apenas como professores, mas também como psicólogos, policiais, pais, motivadores, etc.

O trabalho docente se intensificou também em decorrência da ampliação de horas em trabalho coletivo e da participação na vida escolar, pela gestão cada vez mais frequente de alunos do ensino público em dificuldade e pelas exigências crescentes das autoridades políticas e públicas que cobram que os professores se comportem como trabalhadores da indústria, agindo como uma mão de obra flexível, eficiente e barata.

No Quadro 3 são mostrados os fatores que dificultam a prática pedagógica do professor de EF classificados na dimensão Institucional/Organizacional. Essas dificuldades estão relacionadas com questões que as próprias redes de ensino não conseguem resolver ou que envolvem a gestão de cada escola.

Quadro 3 - Fatores que dificultam a prática pedagógica do professor de EF na dimensão Institucional/Organizacional.

\begin{tabular}{|l|c|c|c|c|}
\hline $\begin{array}{l}\text { Fatores classificados na dimensão } \\
\text { Institucional/Organizacional }\end{array}$ & Entrevista & $\begin{array}{c}\text { Observação } \\
\text { Fund. 1 }\end{array}$ & $\begin{array}{c}\text { Observação } \\
\text { Fund. 2 }\end{array}$ & Literatura \\
\hline Falta de organização da escola & $\mathrm{x}$ & $\mathrm{X}$ & $\mathrm{x}$ & $\mathrm{x}$ \\
\hline Falta de materiais & $\mathrm{x}$ & $\mathrm{x}$ & $\mathrm{x}$ & $\mathrm{x}$ \\
\hline Barulho causado pelas aulas de EF & $\mathrm{x}$ & & & $\mathrm{x}$ \\
\hline $\begin{array}{l}\text { Formação continuada insuficiente na } \\
\text { escola }\end{array}$ & $\mathrm{x}$ & & & $\mathrm{X}$ \\
\hline $\begin{array}{l}\text { Relação inadequada entre escola e co- } \\
\text { munidade }\end{array}$ & $\mathrm{x}$ & & $\mathrm{X}$ & \\
\hline Mau odor no local da aula de EF & & $\mathrm{X}$ & & \\
\hline Alunos transferidos durante o ano letivo & & & & \\
\hline Falta de organização da rede municipal & $\mathrm{x}$ & $\mathrm{x}$ & & $\mathrm{x}$ \\
\hline Falta de trabalho coletivo & $\mathrm{x}$ & & & \\
\hline Relação interpessoal inadequada & & & & \\
\hline Coordenação Ausente & & & & \\
\hline
\end{tabular}

Fonte: Elaborado pelos autores, 2016.

A falta de organização da rede municipal pesquisada, a falta de trabalho coletivo, a relação interpessoal inadequada, o mau odor no local da aula de EF, e alunos transferidos durante o ano letivo foram identificados em nossa pesquisa e não mencionados na literatura levantada.

Embora muitas dessas questões estejam relacionadas com dificuldades que ocorrem dentro da escola, a maioria não está ligada completamente à didática dos professores. Os profissionais da Educação que participaram da pesquisa confirmaram o que já vem sendo mencionado pela literatura da EFE: os principais entraves da prática pedagógica estão relacionados 
a fatores externos ao momento da aula e externos à organização didático-pedagógica do docente.

Na leitura do Quadro 4, nota-se que poucos fatores foram classificados na dimensão Instrucional/Pedagógica. Esse resultado mostra que as questões ligadas aos métodos de ensino e didática não são as que mais dificultam o trabalho na percepção dos profissionais da Educação pesquisados.

Quadro 4 - Fatores que dificultam a prática pedagógica do professor de EF na dimensão Instrucional/Pedagógica.

\begin{tabular}{|l|c|c|c|c|}
\hline $\begin{array}{l}\text { Fatores classificados na dimensão } \\
\text { Institucional/Organizacional }\end{array}$ & Entrevista & $\begin{array}{c}\text { Observação } \\
\text { Fund. 1 }\end{array}$ & $\begin{array}{c}\text { Observação } \\
\text { Fund. 2 }\end{array}$ & Literatura \\
\hline $\begin{array}{l}\text { Dificuldade dos alunos com os conteú- } \\
\text { dos }\end{array}$ & $\mathrm{x}$ & $\mathrm{X}$ & $\mathrm{x}$ & \\
\hline Falta de atenção dos alunos & & & & $\mathrm{x}$ \\
\hline
\end{tabular}

Fonte: Elaborado pelos autores, 2016.

Os pesquisados não mencionaram questões que poderiam dificultar a sua prática pedagógica na dimensão Instrucional/Pedagógica como a falta de conhecimento do projeto político-pedagógico da escola, a dificuldade de ensinar manifestações da cultura corporal de movimento pouco estimuladas na escola como danças, lutas e ginásticas, nem a falta de tradição da área em planejar e ministrar aulas com conteúdos menos relacionados às modalidades esportivas. As barreiras citadas pelos profissionais pesquisados são as que eles percebem como prejudiciais ao desenvolvimento do caráter pedagógico da EFE durante as aulas.

Para compreender os resultados desta pesquisa, nos foi particularmente útil a teoria de Peter Woods, sobre as "estratégias de sobrevivência", mencionada por Charlot (2013), que descreve o que acontece com os docentes em seu trabalho na escola. Segundo essa teoria, o objetivo prioritário dos professores acaba sendo sobreviver no cotidiano escolar, tanto do ponto de vista profissional, quanto do ponto de vista do próprio bem-estar psicológico. Só depois de garantidas tais condições de sobrevivência, eles se ocupam dos objetivos de formação dos alunos. Portanto, quanto mais difíceis forem as condições de trabalho, o predomínio das estratégias de sobrevivência será maior, e, por consequência, menores serão as discussões e estratégias elaboradas para alcançar os objetivos educacionais dos alunos.

Quando teorias educacionais que geram reflexão sobre a prática pedagógica são apresentadas aos docentes, ocorre uma desestabilização em suas estratégias de sobrevivência. Essa reflexão pode surtir resultado oposto ao desejado uma vez que os docentes podem se fixar nas convicções pedagógicas criadas no interior das estratégias de sobrevivência, esvaziando o sentido de qualquer inovação.

Esse fenômeno também afeta aos professores de EFE que, para permanecer no seu espaço de trabalho, por vezes deixam de lado seus objetivos educacionais devido à baixa remuneração, intensificação do trabalho e condições inadequadas para atuação profissional.

No entanto, mesmo consideradas as inúmeras condições de trabalho adversas, é difícil aceitar que o professor de EF desista de suas intencionalidades pedagógicas e seja visto apenas como vítima, pois ele também pode atuar e provocar mudanças nas estruturas macro e micro que influenciam seu cotidiano (CAPARROZ; BRACHT, 2007).

De acordo com Pérez Gómez (2001), os docentes estabelecem uma cultura que influencia na seleção das estratégias de ensino, nas relações interpessoais entre os funcionários da escola, na definição de papéis e de funções que desempenham, nas estruturas de participação e na forma que os professores tomam diversificadas decisões importantes para cumprir a tarefa educativa. Essa realidade compõe uma estrutura de poder e um equilíbrio de interesses que, 
ainda que parcial e provisório, mostra que os docentes possuem um espaço para agir, caso queiram.

Após realizar as entrevistas e as observações das aulas e suas respectivas análises, realizamos a Re-Configuração do Universo da Pesquisa que consistiu em voltar à escola e realizar a devolutiva dos conhecimentos produzidos e refletir sobre eles juntamente com os profissionais pesquisados.

A diretora e o coordenador pedagógico fizeram diversos comentários sobre as dificuldades identificadas. Mencionaram a complexidade existente no cotidiano escolar e analisaram as dificuldades mencionadas pelos professores de EF em relação às decisões de cunho organizacional do corpo gestor. Em alguns momentos, criticaram os professores e discordaram de alguns posicionamentos deles.

Ao final dessa devolutiva, o olhar dos pesquisados pareceu mostrar maior compreensão em relação aos resultados produzidos do que no início da conversa. Em outras palavras, essa etapa da pesquisa propiciou que tanto os profissionais pesquisados, quanto os pesquisadores, pensassem melhor nas dificuldades enfrentadas pelos professores de EF na efetivação da sua prática pedagógica naquela escola.

Os três professores de EF que participaram da pesquisa também realizaram suas reflexões ao se darem conta da quantidade de fatores que dificultam a sua prática pedagógica mencionados por todos. Os docentes concordaram com a maioria dos fatores identificados e tiveram a chance de se posicionar frente ao que foi apresentado, realizando uma análise crítica da complexidade existente no cotidiano escolar público.

Surgiram mais menções às dificuldades de relacionamento interpessoal entre os gestores e os professores de EF da escola pesquisada, enfatizando que os conflitos que são gerados durante a relação profissional dificultam de forma importante a prática pedagógica do professor de EF, como também tornam esse processo ainda mais difícil de ser compreendido.

Após o processo de Re-configuração do universo da pesquisa, identificamos que todos os profissionais da Educação que colaboraram com o estudo foram estimulados a refletir e refletiram sobre a sua atuação profissional.

\section{Considerações Finais}

Os resultados mostraram que a efetivação da prática pedagógica do professor de EFE não depende exclusivamente do bom preparo pedagógico ou de sua boa atuação didática, mas é fruto de uma teia de fatores, de relações interpessoais, que envolvem os alunos, a relação da escola com as instâncias superiores da Secretaria Municipal da Educação e decisões políticas que extrapolam o contexto das Secretarias Municipais, às vezes tomadas por pessoas que desconhecem as características do cotidiano escolar.

$\mathrm{O}$ distanciamento existente entre aqueles que escrevem as propostas curriculares e aqueles que enfrentam as adversidades do cotidiano escolar para implementar práticas pedagógicas coerentes com tais propostas é uma dificuldade importante a ser superada.

Existe uma carência generalizada de mecanismos que apoiem a equipe escolar em suas dificuldades administrativas e pedagógicas diárias e estimulem reflexões com os profissionais da Educação em suas escolas. Ficou clara a necessidade da existência de uma rede efetiva de comunicação que vise sintonizar as esferas políticas, administrativas e didáticas, e que colabore para que a equipe escolar não se sinta desorientada no que se refere às ações que devem ser tomadas de forma coerente com a concretização de seja qual for a proposta curricular.

Cada vez mais se percebe o quanto é necessária a aproximação entre as Universidades/redes de pesquisa e a gestão pública da Educação para que o trabalho educativo da equipe escolar possa ter o acompanhamento e o apoio que merece. 
Nossa pesquisa reforçou que os pesquisadores aprendem com as pessoas do universo pesquisado e o quanto é importante que os resultados da pesquisa retornem à escola para sua validação e ampliação.

Ao identificar que os profissionais da Educação e os docentes de EFE percebem que as barreiras ao desenvolvimento da prática pedagógica se situam, em sua maioria, nas dimensões Sociopolítica/Cultural e Institucional/Organizacional, a pesquisa permitiu compreender que os pesquisados construíram todo um contexto de justificativas que levam a crer que os docentes não são os únicos responsáveis pelo descompasso entre o ideário manifestado nos documentos das propostas curriculares oficiais e sua implementação nas escolas e como cotidiano escolar é realmente um fenômeno complexo.

Para melhor compreender os fatores que dificultam a prática pedagógica do professor de EFE, sugerimos ampliação do universo pesquisado, incluindo mais escolas, mais atores escolares, alunos e seus pais, bem como dando voz aos gestores centrais das redes de ensino, e aos políticos que acabam por deliberar sobre aspectos que afetam a vida na escola.

\title{
PEDAGOGICAL PRACTICE OF THE PHYSICAL EDUCATION TEACHER AT SCHOOL: DIFFICULTIES PERCEIVED BY A SCHOOL TEAM IN THE CITY OF SÃO PAULO
}

\begin{abstract}
The objective of this study was to identify and understand the factors that make the pedagogical work of Physical Education difficult at school through a qualitative, descriptive research carried out in a municipal school of the city of São Paulo. The main factors found were: professional discontent, long working hours, low pay, insufficient professional training and work disorganization. After performing the analysis and classification of factors found, we concluded that they are present in the Sociopolitical/Cultural, Institutional/Organizational, Instructional/Pedagogical dimensions, being more frequent in the first two and, therefore, the teacher is not the only responsible for mismatch between the ideals of official curricular proposals and their implementation at schools.

Keywords: Physical education. Pedagogical practice. School context. Difficulties.

\section{PRÁCTICA PEDAGÓGICA DEL PROFESOR DE EDUCACIÓN FÍSICA EN LA ES- CUELA: DIFICULTADES OBSERVADAS POR UN EQUIPO ESCOLAR EN LA CIUDAD DE SÃO PAULO}

\section{Resumen}

Buscamos comprender los factores que dificultan las acciones pedagógicas de los profesores de Educación Física Escolar a través de una investigación cualitativa, descriptiva, desarrollada en una escuela pública municipal de la ciudad de São Paulo. Los principales factores encontrados fueron: insatisfacción profesional, jornada de trabajo extensa, sueldos bajos, formación profesional insuficiente y desorganización del trabajo. Después del análisis y de la clasificación de los factores identificados, concluimos que esos factores forman parte de las dimensiones Sociopolítica/Cultural, Institucional/Organizacional, Instruccional/Pedagógica, siendo más frecuentes los dos primeros, concluimos que el maestro no es el único responsable por los desajustes entre los ideales de las propuestas curriculares y su aplicación en las escuelas. |

Palabras clave: Educación Física. Práctica pedagógica. Rutina escolar. Dificultades. 


\section{Referências}

ANDRÉ, M. E. D. A. Etnografia da Prática Escolar. 14. ed. São Paulo: Papirus, 2008.

BERNARDI, G. B.; MOLINA NETO, V. Implicações da proletarização do trabalho docente na Educação Física Escolar. Pensar a Prática, Goiânia, v. 19, n. 2, p. 339-349, 2016.

BOSSLE, F.; MOLINA NETO, V. No "olho do furacão": uma autoetnografia em uma escola da rede municipal de ensino de Porto Alegre. Revista Brasileira de Ciências do Esporte, Campinas, v. 31, n. 1, p. 131-146, 2009.

BOSSLE, F.; MOLINA NETO, V.; WITTIZORECKI, E. S. Sobre “a vida como ela é”: os professores de Educação Física e as violências na escola pública municipal de Porto Alegre. Movimento, Porto Alegre, v. 19, n. 4, p. 47-67, 2013.

CAPARROZ, F. E. Entre a Educação Física na escola e a Educação Física da escola. 3. ed. Campinas, SP: Autores Associados, 2007.

CAPARROZ, F. E.; BRACHT, V. O tempo e o lugar de uma didática da Educação Física. Revista Brasileira de Ciências do Esporte, Campinas, v. 28, n. 2, p. 21-37, 2007.

CHARLOT, B. Da relação com o saber às práticas educativas. São Paulo: Cortez, 2013.

CLARO JUNIOR, R. S.; FILGUEIRAS, I. P. Dificuldades de gestão de aula de professores de Educação Física em início da carreira na escola. Revista Mackenzie de Educação Física e Esporte, v. 8, n. 2, p. 9-24, 2009.

COLETIVO DE AUTORES. Metodologia do ensino da Educação Física. 2. ed. São Paulo: Cortez, 2009.

DAMAZIO, M. S.; SILVA, M. F. P. O ensino da Educação Física e o espaço físico em quês tão. Pensar a Prática, Goiânia, v. 11, n. 2, p. 197-207, 2008.

LAVILLE, C; DIONNE, J. A construção do saber: manual de metodologia da pesquisa em ciências humanas. Porto Alegre: UFMG, 1999.

FERREIRA, L. A. Docência. In: GONZÁLEZ, F. J.; FENSTERSEIFER, P. E. Dicionário Crítico da Educação Física. 3. ed. Ijuí: Unijuí, 2014.

FOLLE, A.; NASCIMENTO, J. V. Preocupações ao longo da carreira docente: estudos de caso com professores do magistério público estadual. Revista Brasileira de Ciências do Esporte, Campinas, v. 33, n. 4, p. 841-856, 2011.

FREIRE, J. B. Educação de Corpo Inteiro: teoria e prática da Educação Física. Campinas: Scipione, 1989.

GASPARI, T. C. et al. A realidade dos professores de Educação Física na escola: suas dificuldades e sugestões. Revista Mineira de Educação Física, Viçosa, v. 14, n. 1, p. 109-137, 2006. 
GUEDES, D. P. Educação para saúde mediante programas de Educação Física Escolar. Motriz, Rio Claro, v. 5, n. 1, jun. 1999.

JARAMILLO ECHEVERRI, L. G. La complementariedad como posibilidad para investigar en motricidad y desarrollo humano. In: TRIGO AZA, E. et al. (Org.). Consentido. Cauca: Universidade de Cauca, 2005.

KUNZ, E. Transformação didático-pedagógica do esporte. 4. ed. Ijuí: Unijuí, 2001.

LE BOULCH, J. A educação pelo movimento: a psicocinética na idade escolar. Porto Alegre: Artes Médicas, 1983.

LEVANDOSKI, G.; OGG, F.; CARDOSO, F. L. Violência contra professores de Educação Física no ensino público do Estado do Paraná. Motriz, Rio Claro, v. 17, n. 3, p. 374-383, 2011.

LIBÂNEO, J. C. Organização e gestão da escola: teoria e prática. 6. ed. São Paulo: Heccus, 2015.

MACHADO, T. S. et al. As práticas de desinvestimento pedagógico na Educação Física escolar. Movimento, Porto Alegre, v. 16, n. 2, p. 129-147, 2010.

MAGALHÃES, C. H. F.; MARTINELI, T. A. P. Soluções formais no enfrentamento de problemas da prática escolar. O estranhamento dos professores de Educação Física Escolar. Motrivivência, ano XXIII, n. 36, 2011.

MALDONADO, D. T.; SILVA, S. A. P. S.; MIRANDA, M. L. J. Pesquisas sobre Educação Física no cotidiano da escola: o estado da arte. Movimento, Porto Alegre, v. 20, n. 4, p. 13731395, out./dez. 2014.

MARTINS, J.; BICUDO, M. A. V. A Pesquisa Qualitativa em Psicologia: fundamentos e recursos básicos. 5. ed. São Paulo: Centauro, 2005.

MIRON, E. M.; COSTA, M. P. R. Barreiras físicas e o acesso às aulas de Educação Física. Pensar a Prática, Goiânia, v. 17, n. 2, p. 377-394, 2014.

NEIRA, M. G.; NUNES, M. L. F. Educação Física, currículo e cultura. São Paulo: Phorte, 2009.

OLIVEIRA, C. F.; SILVA, L. O.; MOLINA NETO, V. Arquitetura escolar e o ensino de Educação Física: relações (im)possíveis. Pensar a Prática, Goiânia, v. 14, n. 2, p. 1-10, 2011.

PÉREZ GÓMEZ, A. I. A cultura escolar na sociedade neoliberal. Porto Alegre: Artmed, 2001.

PORATH, M. et al. Fases de desinvestimento da carreira docente de professores de Educação Física. Movimento, Porto Alegre, v. 17, n. 4, p. 203-222, 2011.

REIS, R. L. Percepção do educador físico sobre a escola pública. Conexões: Revista da Faculdade de Educação Física da UNICAMP, Campinas, v. 7, n. 1, p. 77-97, 2009. 
REZER, R.; FENSTERSEIFER, P. E. Docência em Educação Física: reflexões acerca de sua complexidade. Pensar a Prática, Goiânia, v. 11, n. 3, p. 319-329, 2008.

RODRIGUES, L. L.; BRACHT, V. As culturas da Educação Física. Revista Brasileira de Ciências do Esporte, Campinas, v. 32, n. 1, p. 93-107, 2010.

ROSSI, F.; HUNGER, D. Dilemas contemporâneos da profissão professor: perspectivas de professores (as) de Educação Física da rede pública estadual de São Paulo. Revista Mackenzie de Educação Física e Esporte, v. 12, n. 2, p. 42-58, 2013.

SACRISTÁN, G. O currículo: os conteúdos de ensino ou uma análise da prática? In: SACRISTÁN, G.; PÉREZ GÓMEZ, A. I. Compreender e Transformar o Ensino. 4. ed. São Paulo: Artmed, 1998.

SANT'ANA, A. S. S.; NASCIMENTO, J. V.; AZEVEDO, E. S. Fatores associados à indisciplina nas aulas de Educação Física. Revista Brasileira de Ciência e Movimento, v. 20, n. 1, p. 78-87, 2012.

SANTINI, J.; MOLINA NETO, V. A síndrome do esgotamento profissional em professores de educação física: um estudo na rede municipal de ensino de Porto Alegre. Revista Brasileira de Educação Física e Esporte, São Paulo, v. 19, n. 3, p. 209-222, 2005.

SILVA, S. A. P. S. Portas abertas para a Educação Física: falando sobre abordagens pedagógicas. São Paulo: Phorte, 2013.

TANI, G. et al. Educação Física Escolar: fundamentos de uma abordagem desenvolvimentista. São Paulo: EPU, 1988.

TARDIF, M. A profissionalização do ensino passados trinta anos: dois passos para a frente, três passos para trás. Educação e Sociedade, v. 34, n. 123, p. 551-571, 2013.

TENÓRIO, M. C. M.; TASSITANO, R. M.; LIMA, M. C. Conhecendo o ambiente escolar para as aulas de Educação Física: existe diferenças entre as escolas? Revista Brasileira de Atividade Física e Saúde, v. 17, n. 4, p. 307-313, 2012.

TOKUYOCHI, J. H. et al. Retrato dos professores de Educação Física das escolas estaduais do estado de São Paulo. Motriz, Rio Claro, v. 14, n. 4, p. 418-428, 2008.

Recebido em: 30/06/2016

Revisado em: 16/01/2016

Aprovado em: 06/02/2017

Endereço para correspondência:

danieltmaldonado@yahoo.com.br

Daniel Teixeira Maldonado

Universidade São Judas Tadeu, Curso de Educação Física.

Rua Taquari, 546

Mooca

03166-000 - Sao Paulo, SP - Brasil 